\title{
SDF-1 and its receptor in the ventricles of rat with monocrotaline-induced pulmonary hypertension
}

Original research article/Review

\author{
Veteskova J. ${ }^{凶}$, Obsivan M., Kmecova Z., Radik M., Srankova J., Malikova E., Klimas J., Krenek P. \\ Comenius University in Bratislava, \\ Faculty of Pharmacy, Department \\ of Pharmacology and Toxicology, \\ Bratislava, Slovak Republic
}

Received 2 May, 2018, accepted 4 June, 2018

Abstract Aim: Chemokine stromal cell derived factor-1 (SDF-1) plays an important role in many processes such as apoptosis, proliferation, migration and angiogenesis, and these effects are mediated mostly by the receptor CXCR4. The aim of this study was to determine the expression of SDF-1 and CXCR4 in the ventricles of rats with monocrotaline-induced pulmonary hypertension.

Methods: 10-12 weeks old male Wistar rats were injected with monocrotaline (s. c., $60 \mathrm{mg} / \mathrm{kg} ; \mathrm{MON}$ ) or vehicle (CON). Rats were sacrificed 1 week (1W-MON, 1W-CON), 2 weeks (2W-MON, 2W-CON) and 4 weeks after monocrotaline administration (4W-MON, 4W-CON). Gene expression of SDF-1 and CXCR4 was determined by qRT-PCR.

Results: We observed a decrease in the SDF-1 expression on mRNA level in the right ventricle in $2 \mathrm{~W}-\mathrm{MON}$ and $4 \mathrm{~W}-\mathrm{MON}$ rats without any changes in the left ventricles and a decrease in CXCR4 expression in 1W-MON in both ventricles with an increase of CXCR4 expression in 4W-MON in the left ventricle ( $* \mathrm{P}<0.05)$

Conclusion: SDF-1/CXCR4 axis is affected in both ventricles of rats with monocrotaline model of pulmonary hypertension. Keywords: Pulmonary hypertension, monocrotaline, stromal cell-derived factor 1, ventricles

Keywords Pulmonary hypertension-monocrotaline-stromal cell derived factor-1 - ventricles

\section{INTRODUCTION}

Pulmonary hypertension $(\mathrm{PH})$ is defined as an increase in the mean pulmonary arterial pressure over $25 \mathrm{mmHg}$ at rest measured by the right heart catheterization (Hoeper et al., 2013). PH is an orphan disease (European PH prevalence is 15-60 subjects per million population) (Galiè et al., 2015); however, its development is quite progressive and fatal (almost 50\% mortality rate in 3 years without treatment) (Lai et al., 2014). Elevation of pulmonary arterial pressure along with remodelling of the pulmonary arterial vessels increase the right ventricular (RV) afterload, thus contributing to the development of RV dysfunction and failure (Bogaard et al., 2009). Current therapeutic approach for PH has evolved with increase in complexity, which arises from the complex molecular mechanism of PH development (Galie et al., 2015). Recently, it has been noticed that stromal cell derived factor-1 (SDF-1) concentration were elevated in the plasma of patients with pulmonary arterial hypertension compared to healthy controls. Furthermore, the elevated circulating SDF-1 seems to be an independent risk factor for reduced survival in these patients (McCullagh et al., 2015). SDF-1 was originally identified as a molecule secreted in the bone marrow stromal cell lines attracting and stimulating the growth of B-cells (Bleul et al., 1996). As a ligand for chemokine (C - X - C motif) receptor 4 (CXCR4), SDF-1 plays a role in the recruitment of stem cells to areas of tissue injury in multiple organ system. CXCR4 receptor has been described as an essential chemokine receptor for development, haematopoiesis, organogenesis and vascularization (Wang et al., 2014). Increase in expression of CXCR4 and SDF-1 in lungs of hypoxia-induced PH mice (Gambaryan et al., 2011) or pulmonary arterial pressure reduction, attenuation of right ventricle hypertrophy and wall thickness of pulmonary arteries with CXCR4 inhibition in hypoxic-induced $\mathrm{PH}$ rats (Yu et al., 2011) indicate that of SDF$1 /$ CXCR4 axis also takes part in hypoxic model of $\mathrm{PH}$. Hypoxia stimulates the expression of CXCR4 in endothelial cells and also potentiates migratory response of endothelial cells to exogenous SDF-1 (Schioppa et al., 2003). Increased SDF-1 levels were also demonstrated in the decompensated right ventricle of monocrotaline-induced $\mathrm{PH}$ in rats (Sutendra et al., 2013). 
In our study, we aim to determine the involvement of SDF1 and CXCR4 receptor in the ventricles of monocrotalineinduced $\mathrm{PH}$ rats in development of the disease.

\section{METHODS}

\section{Experimental Design}

10-12 weeks old male Wistar rats were administered a single dose of monocrotaline (Sigma Aldrich, USA) injection (s. c., $60 \mathrm{mg} / \mathrm{kg}, \mathrm{MON}$ ) or vehicle (CON). Animals were handled under standard conditions with free access to food and drinking water. All experimental procedures involving experimental animals were approved by a local Ethical Committee and the State Veterinary and Food Administration of the Slovak Republic. Rats were sacrificed 1, 2 or 4 weeks after monocrotaline administration (1W-CON, 1W-MON; 2W-CON, 2W-MON;4W-CON, 4W-MON) and tissue samples from right and left ventricle were isolated.

\section{Gene Expression}

Total RNA was isolated from the samples by phenol/chloroform extraction using Tri-Reagent (Sigma Aldrich, USA). Quality of isolated RNA was verified by agarose gel electrophoresis and spectrophotometric analysis (NanoDropND-1000, Thermo Scientific, USA). Total RNA were reverse-transcribed to cDNA (High capacity cDNA Reverse Transcription Kit, Applied Biosystems, USA) and real-time PCR (StepOne Plus System, Applied Biosystem, USA) was performed using SYBR green PCR Master Mix kit (Applied Biosystems, USA). Expression of SDF-1 and CXCR4 were determined using gene specific primers (Srankova et al., 2016). All primers were verified to yield a single PCR product with the correct molecular weight. Beta-2-microglobulin was used as endogenous reference gene and results were calibrated to the control groups.

\section{Statistical Analysis}

Results are expressed as average \pm standard error of the mean. Mean PCR efficiency estimates per amplicon and quantification cycle $(\mathrm{Cq})$ values per sample were determined with LinRegPCR software (version 2015.0) and relative expression were calculated (Doka et al., 2017). Statistical significance was determined by a non-parametric MannWhitney test or parametric t-test after Shapiro-Wilk's test of normality. Differences were considered significant at $P<0.05$. Results were analysed by GraphPad Prism 4.0 (GraphPad Software, California).

\section{RESULTS}

We observed a decrease in the relative expression of SDF-1 on mRNA level in the right ventricle in $2 \mathrm{~W}-\mathrm{MON}$ and $4 \mathrm{~W}-\mathrm{MON}$ rats, however, without any changes in the left ventricle in all

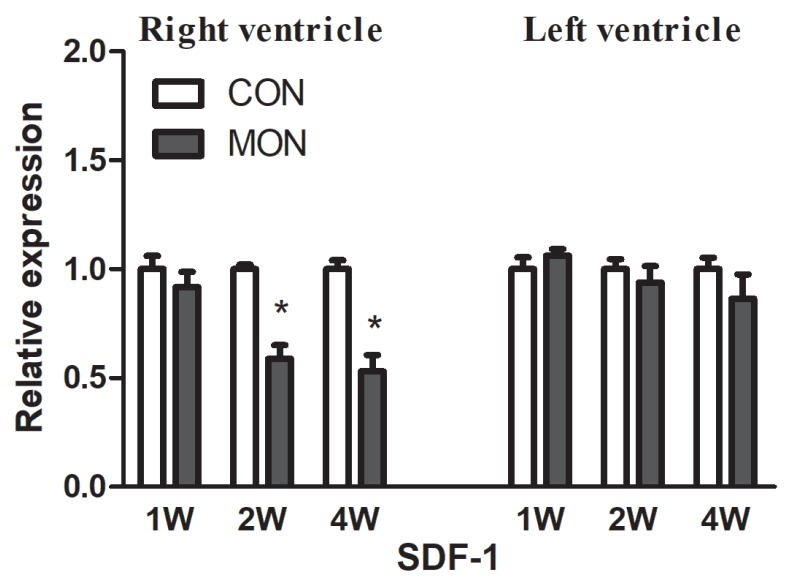

Figure 1. Relative expression of SDF-1 determined by $q R T$ $P C R$ in the right and the left ventricle in 1,2 and 4 weeks after monocrotaline administration. Results are expressed as average \pm SEM. ${ }^{*} P<0.05$ vs. CON.

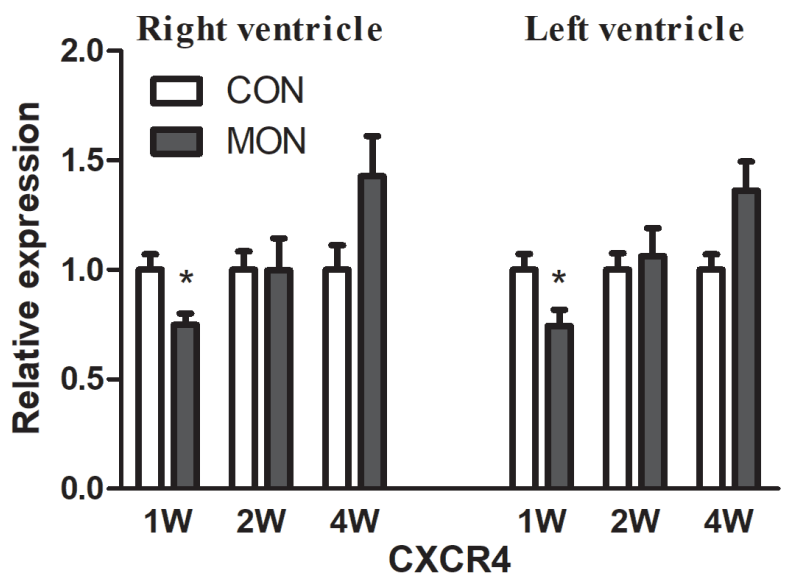

Figure 2. Relative expression of CXCR4 receptor determined by $q R T-P C R$ in the right and the left ventricle in 1,2 and 4 weeks after monocrotaline administration. Results are expressed as average \pm SEM. ${ }^{*} P<0.05$ vs. CON.

observed weeks (Figure 1). A small, but significant decrease of expression of receptor CXCR4 were determined in 1W-MON rats in both ventricles. Elevated expression of CXCR4 was observed in $4 \mathrm{~W}-\mathrm{MON}$ animals in the left ventricle (Figure 2).

\section{DISCUSSION}

We aimed to determine the expression of SDF-1 during the development of monocrotaline-induced $\mathrm{PH}$. In this model, the severe $\mathrm{PH}$ stage with elevated RV pressure, RV hypertrophy and clinical signs of $\mathrm{PH}$ (dyspnoea, cachexia, loss of social interactions) develops approximately 4 weeks after monocrotaline administration. In the early stages of the model ( 1 or 2 weeks after monocrotaline administration), none of these features occur (data not shown), despite the supposed endothelial cell injury (Gomez-Arroyo et al., 2012). 
We found that SDF-1 expression on mRNA level was decreased 2 and 4 weeks after monocrotaline administration. Sutendra et al. linked SDF-1 expression in the developed stages of monocrotaline $\mathrm{PH}$ to $\mathrm{RV}$ function as they recognised the elevation of SDF-1 expression in the compensated RV failure and SDF-1 decrease in decompensated right ventricular failure with high mortality rate and severe $\mathrm{PH}$ symptoms (Sutendra et al., 2013).

Influence of SDF-1 on heart tissue has been seen in the models of systemic hypertension or cell culture systems. Increase of SDF-1 was described in spontaneously hypertensive rats, which further increased with aging (Shao et al., 2015). SDF-1 on cultures of myofibroblast increased the migration of myofibroblasts and wound healing (Shao et al., 2015), treatment with exogenous SDF-1 has concentrationdependent effects on proliferation, hypertrophy and collagen production in activated cardiac fibroblasts from normotensive and hypertensive rats (Jackson et al., 2017). All these effects were almost completely blocked with antagonist of CXCR4 receptor AMD3100 (Shao et al., 2015; Jackson et al., 2017). Whether SDF-1 is associated with improvement of cardiac function or further drives pathological changes in the hearts in $\mathrm{PH}$ models remains to be elucidated.

Data from the models of $\mathrm{PH}$ are almost completely from work on hypoxic models and effects of SDF-1 on lung vasculature. Not only SDF-1, but also CXCR4 was elevated in lungs of hypoxic-induced PH mice and antagonism with AMD3100 partially improved right ventricular pressure (Gambaryan et al., 2011). In hypoxic rat model of PAH, an increase in SDF1 preceded the development of complex inflammatory microenvironment in lungs and pulmonary artery and an increase in the expression of SDF-1 was parallel to an increase in the CXCR4 expression (Burke et al., 2009). In our study, CXCR4 expression seems to be independent on the SDF-1 mRNA level as we have seen a decrease in the CXCR4 expression in 1W-MON animas in both ventricles, where SDF-1 was not changed. Treatment with CXCR4 inhibitor in hypoxiainduced $\mathrm{PH}$ rats improved RV pressure, RV hypertrophy and prevented increased wall thickness of pulmonary arteries. Also, electroporation of bone marrow cells with the CXCR4 shRNA inhibited the development of hypoxia-induced $\mathrm{PH}$ and lung vasculature remodelling (Yu et al., 2011).

SDF-1 can act beside CXCR4 receptor also on CXCR7 receptor, but data about CXCR7 in PH models are to this date limited to one study from Gambaryan et al., where they noticed the elevation of CXCR7 in lungs of hypoxic-induced PH mice and antagonism of this receptor only partially improved RV pressure. However, in combination with CXCR4 antagonism significant pressure and RV hypertrophy reduction were determined (Gambaryan et al., 2011).

\section{CONCLUSION}

In conclusion, we determined a decrease in SDF-1 in right ventricle in monocrotaline model of $\mathrm{PH}$ and also changes in CXCR4 expression. Involvement of SDF-1/CXCR4 axis in the development of $\mathrm{PH}$ is undeniable as we can see not only from our study, but also from elevation of SDF-1 in plasma of patients with pulmonary arterial hypertension. Since SDF-1/ CXCR4 axis is pharmacologically modifiable, it remains to be further studied in $\mathrm{PH}$.

\section{ACKNOWLEDGEMENT}

The work was supported by the grant APVV-15-0685 Theranostic potential of components of alternative RAS in modulation of right ventricular function and dysfunction from the Slovak Research and Development Agency (Jan Klimas) and grant 1/0294/15 from the Science Grant Agency (VEGA), Slovak Republic (Peter Krenek).

\section{References}

[1] Bleul CC, Fuhlbrigge RC, Casasnovas JM, Aiuti A, Springer TA. A highly efficacious lymphocyte chemoattractant, stromal cellderived factor 1 (SDF-1). J Exp Med. 1996;184(3):1101-9.

[2] Bogaard HJ, Abe K, Vonk Noordegraaf A, Voelkel NF. The right ventricle under pressure: cellular and molecular mechanisms of right-heart failure in pulmonary hypertension. Chest. 2009;135(3):794-804.

[3] Burke DL, Frid MG, Kunrath CL et al. Sustained hypoxia promotes the development of a pulmonary artery-specific chronic inflammatory microenvironment. Am J Physiol Lung Cell Mol Physiol. 2009;297(2):L238-50.

[4] Doka G, Malikova E, Galkova K et al. Downregulation of myogenic microRNAs in sub-chronic but not in sub-acute model of daunorubicin-induced cardiomyopathy. Mol Cell Biochem. 2017;432(1-2):79-89.

[5] Gambaryan N, Perros F, Montani D et al. Targeting of c-kit+ haematopoietic progenitor cells prevents hypoxic pulmonary hypertension. Eur Respir J. 2011;37(6):1392-9.
[6] Galiè N, Humbert M, Vachiery JL et al. 2015 ESC/ERS Guidelines for the Diagnosis and Treatment of Pulmonary Hypertension. Rev Esp Cardiol (Engl Ed). 2016;69(2):177.

[7] Gomez-Arroyo JG, Farkas L, Alhussaini AA et al.The monocrotaline model of pulmonary hypertension in perspective. Am J Physiol Lung Cell Mol Physiol. 2012;302(4):L363-9.

[8] Hoeper MM, Bogaard HJ, Condliffe R et al. Definitions and diagnosis of pulmonary hypertension. J Am Coll Cardiol. 2013;62(25 Suppl):D42-50.

[9] Jackson EK, Zhang Y, Gillespie DD, Zhu X, Cheng D, Jackson TC. SDF-1a (Stromal Cell-Derived Factor 1a) Induces Cardiac Fibroblasts, Renal Microvascular Smooth Muscle Cells, and Glomerular Mesangial Cells to Proliferate, Cause Hypertrophy, and Produce Collagen. J Am Heart Assoc. 2017;6(11).

[10] Lai YC, Potoka KC, Champion HC, Mora AL, Gladwin MT. Pulmonary arterial hypertension: the clinical syndrome. Circ Res. 2014;115(1):115-30. 
[11] McCullagh BN, Costello CM, Li L et al. Elevated plasma CXCL12a is associated with a poorer prognosis in pulmonary arterial hypertension. PLoS One. 2015;10(4):e0123709.

[12] Schioppa T, Uranchimeg B, Saccani A et al. Regulation of the chemokine receptor CXCR4 by hypoxia. J Exp Med. 2003;198(9):1391-402.

[13] Shao S, Cai W, Sheng J, Yin L. Role of SDF-1 and Wnt signaling pathway in the myocardial fibrosis of hypertensive rats. Am J Transl Res. 2015;7(8):1345-56.

[14] Srankova J, Doka G, Pivackova L et al. Daunorubicin DownRegulates the Expression of Stem Cell Markers and Factors Involved in Stem Cell Migration and Homing in Rat Heart in Subchronic but not Acute Cardiomyopathy. Basic Clin Pharmacol Toxicol. 2016;119(5):443-452.

[15] Sutendra G, Dromparis P, Paulin R et al. A metabolic remodeling in right ventricular hypertrophy is associated with decreased angiogenesis and a transition from a compensated to a decompensated state in pulmonary hypertension. J Mol Med (Berl). 2013;91(11):1315-27.

[16] Yu L, Hales CA. Effect of chemokine receptor CXCR4 on hypoxiainduced pulmonary hypertension and vascular remodeling in rats. Respir Res. 2011;12:21.

[17] Wang ER, Jarrah AA, Benard L et al. Deletion of CXCR4 in cardiomyocytes exacerbates cardiac dysfunction following isoproterenol administration. Gene Ther. 2014;21(5):496-506. 